\title{
Strengthening the evaluation and research unit of the Zimbabwe Family Planning Council (1995-1998)
}

Lewis Ndhlovu

Hazel M.B. Dube

Caroline S. Marangwanda

Follow this and additional works at: https://knowledgecommons.popcouncil.org/departments_sbsr-rh

Part of the Demography, Population, and Ecology Commons, Health Services Research Commons, and the International Public Health Commons

How does access to this work benefit you? Let us know!

\section{Recommended Citation}

Ndhlovu, Lewis, Hazel M.B. Dube, and Caroline S. Marangwanda. 1999. "Strengthening the evaluation and research unit of the Zimbabwe Family Planning Council (1995-1998)." New York: Population Council and the Zimbabwe National Family Planning Council. 
STRENGTHENING THE EVALUATION AND RESEARCH UNIT OF THE ZIMBABWE FAMILY PLANNING COUNCIL (1995-1998)
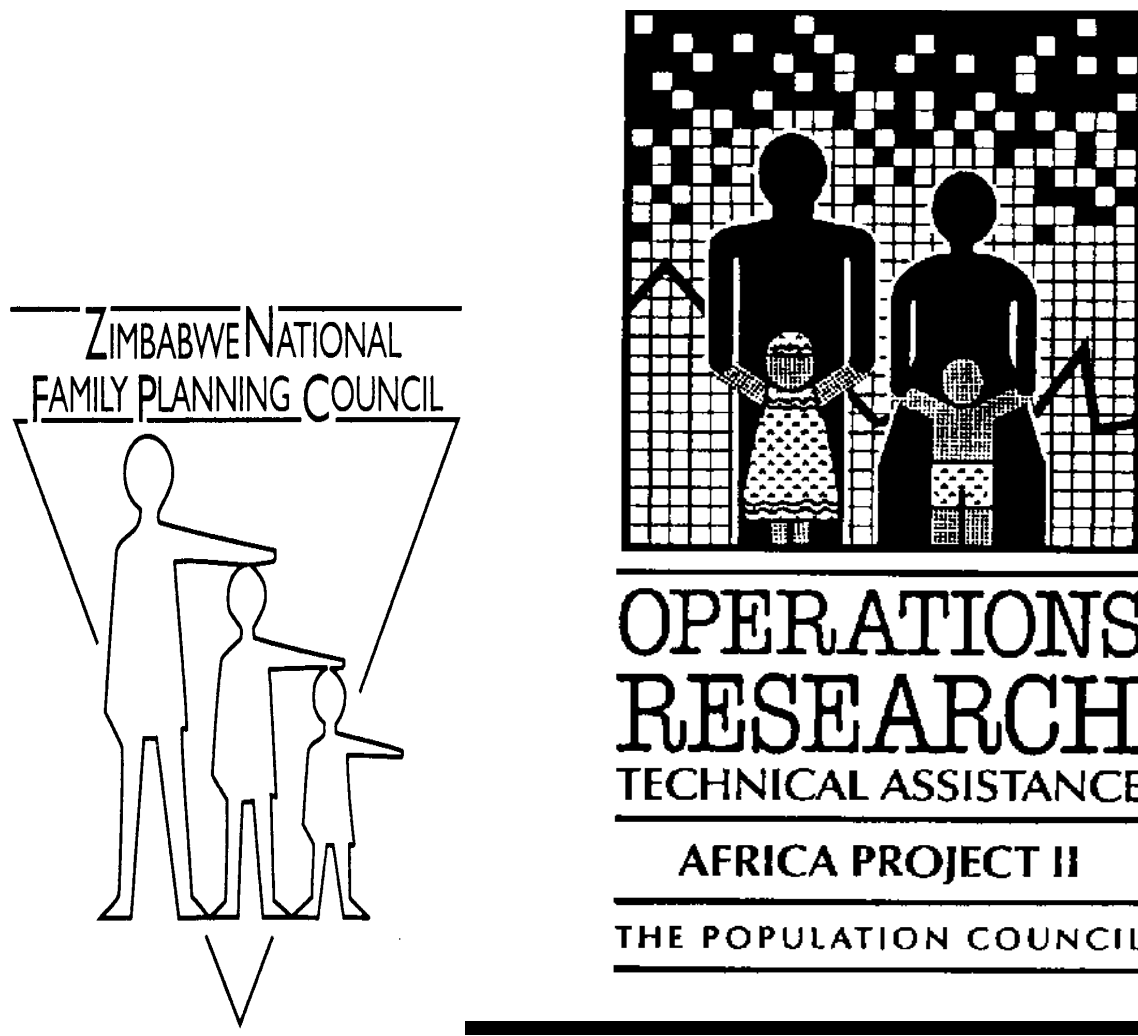

OPERATIONS

RESEARCH TECHNICAL ASSISTANCE

AFRICA PROJECT II

THE POPULATION COUNCIL

Hazel M.B. Dube \& Caroline S. Marangwanda Lewis Ndhlovu

Evaluation and Research Unit,

Zimbabwe National Family,

Planning Council,

Harare,

ZIMBABWE
Population Council,

Nairobi,

KENYA

January 1999 


\section{The Population Council}

The Population Council seeks to help improve the well-being and reproductive health of current and future generations around the world and to help achieve a humane, equitable and sustainable balance between people and resources. The Council analyzes population issues and trends; conducts biomedical research to develop new contraceptives; works with public and private agencies to improve the quality and outreach of family planning and reproductive health services; helps governments to influence demographic behavior; communicates the results of research in the population field to appropriate audiences; and helps build research capacities in developing countries. The Council, a nonprofit, nongovernmental research organization established in 1952, has a multinational Board of Trustees; its New York headquarters supports a global network of regional and country offices.

\section{Africa OR/TA Project II}

The overall objective of the Africa OR/TA Project II is to broaden understanding of how to improve family planning services in Sub-Saharan Africa, and to apply operations research and technical assistance to improve services by:

- increasing access to a full range of family planning services and methods;

- developing service delivery strategies that are client-oriented and acceptable to various population groups;

- improving the operations of programs to make them more efficient and financially sustainable;

- improving the quality of services;

- Strengthening the capabilities of family planning program managers to use operations research to diagnose and solve service delivery problems.

This project was supported by the Population Council's Operations Research and Technical Assistance Project II. The Africa OR/TA Project II is funded by the U.S. Agency for International Development (USAID), Office of Population, Contract No. CCC-3030-C-00-3008-00, Strategies for Improving Family Planning Service Delivery. 



\section{TABLE OF CONTENTS}

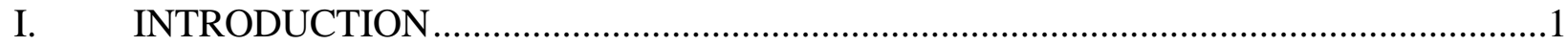

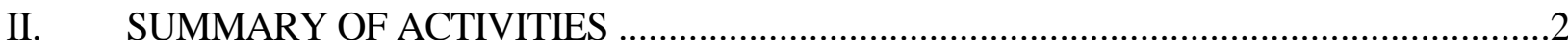

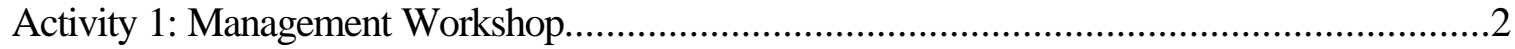

Activity 2: Establishment of Database of Consultants and Researchers .................................2

Activity 3: Training in Statistical Computing ................................................................

Activity 4: Technical Support in developing the second

5 year Strategic Plan for the ERU ..................................................................... 3

Activity 5: Computer Training for administrative secretaries .............................................4

Activity 6: Using the Situation Analysis and the STIs Studies.............................................4

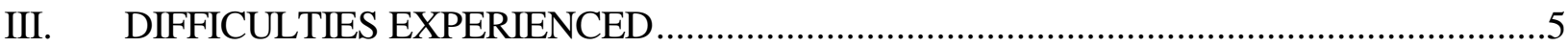

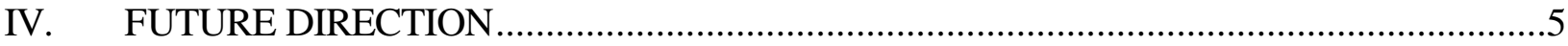




\section{INTRODUCTION}

The Evaluation and Research Unit (ERU) plays a crucial role in supporting research activities of the Zimbabwe National Family Planning Council (ZNFPC). In almost all research efforts in the Council, the Unit is called upon to play a leading role. Research activities are conducted in addition to the routine analysis of service statistics and compilation of quarterly and annual reports. With a staff capacity of five and the inadequate research skills existing in other units, the ERU finds it difficult to manage and monitor the diverse activities of the organization. A review of the studies conducted by the Zimbabwe National Family Planning Council's (ZNFPC) Evaluation and Research Unit (ERU) prior to May 1995 showed that the Unit was understaffed and the officers were generally overworked.

The mechanism to address the problems of the ERU was through a buy-in, which was signed between the Zimbabwe Government and USAID in May 1995. The objectives of the buy-in project were to assist the ZNFPC to conduct operations research studies and, in particular to strengthen the research capacity of the Evaluation and Research Unit. To enable the ERU to function effectively, its traditional role of implementing research had to be revised to that of research management. The ZNFPC requested the Population Council's Africa OR/TA Project to provide technical assistance to implement this new role.

Later in the September 1995, the ZNFPC convened a meeting of co-operating agencies, donors, government and municipal departments to explore ways of improving the co-ordination and implementation of the population activities in Zimbabwe. A number of recommendations from the meeting were developed and the Africa OR/TA Project used these as guidelines for designing future programs for strengthening the research capacity of the ERU. Some of the important recommendations from the meeting were:

i) The problem of shortages of qualified staff within the ZNFPC and the organisation's limited absorptive capacity was noted. To address this problem, it was recommended that concerned agencies should practice better planning and coordination as well as incorporating use of external resources, including local consultants.

ii) The Evaluation and Research Unit should seek local consultants and research firms who could help alleviate some of the ERU's burden resulting from staff shortages.

iii) In conformity with the ZNFPC's strategy to decentralise its activities, it was recommended that research and evaluation skills should be built within each unit and at lower levels.

iv) The ZNFPC should participate in the Ministry of Health and Child Welfare plans for Health Sector Reform in order to implement effective ways to decentralisation. 
v) It was recommended that the ZNFPC should convene quarterly meetings for all the donors to improve coordination.

Based on this meeting and discussions with ZNFPC staff members, a number of research activities were formulated to build the research capacity of the ERU. Firstly, a workshop was conducted to examine the skills that were available in the Unit. Secondly, the ERU was to build a database of consultants with skills in population research. Computing and statistical skills of staff members of the Evaluation and Research Unit were to be upgraded. In addition, two operations research studies were planned and these were to serve as training ground for the Unit staff. A more detailed description of the activities follows.

\section{SUMMARY OF ACTIVITIES}

\section{Activity 1: Management Workshop}

In April 1996, The Africa OR/TA and the staff from the ERU conducted a workshop in order to plan the Unit's activities in terms of its revised role from research implementation to research management. This workshop identified the ERU staff's research management skills in short supply. A needs assessment of the staff's skills showed that each staff member had different skills requirement. Some of the skills that were identified as lacking were in computing, advanced statistical analysis, proposal writing, qualitative research analysis, research management and subcontracting procedures. The Unit's work plan and activities were evaluated and it was found that lack of an ERU-specific budget resulted in the ERU responding more to other ZNFPC Units' needs (because they had a specific budget for their research-activities). In addition, it was also noted that the ERU was not coming up with its own research agenda.

As pointed out earlier, a meeting convened by USAID at Mazvikadei (November, 1995) had noted that the Evaluation and Research Unit was over-burdened with work and, therefore, needed to subcontract some of the activities to other organisations.

Based on this analysis, a project proposal was developed to address these shortcomings.

\section{Activity 2: Establishment of Database of Consultants and Researchers}

The first step towards using consultants to conduct research activities for the ERU was to take an inventory of available skills within the country. In pursuit of this objective, the ZNFPC awarded ARA-Techtop consultants a contract to design a computerized database of consultants in the population and related fields during the second half of 1995. Massive interest was shown by the large number of individuals and organisations who responded to the advertisement in the print media. 
Once data were received ARA-Techtop, with technical assistance from the Population Council and the ERU, designed the system. The project proceeded well; the computer systems were developed and the database of consultants was created.

Unfortunately, the database that had great potential for use by the ZNFPC and other organisations was never completed and delivered to the ZNFPC. Some problems developed between the ZNFPC and ARA-Techtop and this hampered the delivery of the final product. As a result of this unfortunate situation, the ZNFPC still does not have a complete database of consultants that can be relied upon to draw consultants of different expertise.

\section{Activity 3: Training in Statistical Computing}

The Department of Statistics at the University of Zimbabwe conducted a five days workshop in statistical computing for researchers in the Evaluation and Research Unit (ERU). The workshop, which covered a wide range of statistical topics, was conducted in August 1997 and was designed to enable ERU researchers to conduct more complex data analysis beyond descriptive statistics. Topics covered during the training included techniques in sampling, multiple linear regression and time series analysis.

The participants rated the course highly and, as a result, the Statistics Department and the ERU staff have worked out an arrangement for the department to continue providing support to the ERU. For example, the department staff will continue to provide support in computing services and analysis of data for the study designed to "to assess the potential demand for and effectiveness of integrating STI/HIV services within ZNFPC clinics"

\section{Activity 4: Technical Support in developing the second 5 year Strategic Plan for the ERU}

Between 25th October and 1st November, 1997, Dr Ian Askew and Mr. Lewis Ndhlovu visited Harare to conduct a workshop for the Evaluation and Research Unit to help develop the Unit's strategic plan for the years 1997 to 2002 . Unit Heads attended this meeting from other departments of the ZNFPC.

The mission statement of the Unit defined by the end of the workshop stated that "The Evaluation and Research Unit will contribute towards the provision of sustainable, accessible and high quality RH/FP services in Zimbabwe by:

- Conducting and / or coordinating research activities;

- Ensuring the utilization of research findings and service statistics to guide the program thrusts;

- Marketing research services; and 
- Contributing towards research capacity building within the ZNFPC.

Guided by this mission statement and bearing in mind the overall goals of the national family planning program strategy (1997 to 2002), the following objectives were developed for the ERU:

- To conduct 10 research studies and collaborate with other ZNFPC units on 30 research activities;

- To increase the utilization of research study findings and service statistics for program planning and management;

- To generate up to 15 percent of the ERU's annual operating costs ${ }^{1}$; and

- To impart skills to other ZNFPC Units so that they can conduct research studies, interpret and use research findings with minimal assistance from the ERU.

\section{Activity 5: Computer Training for administrative secretaries}

An important component of capacity building was the training of the two administrative secretaries employed by the ERU. The secretaries attended courses in different software from computer companies in Harare. During the course of 1997 and early 1998, the secretaries took advantage of the opportunity and attended advanced courses in Windows, Quattro Pro, Harvard Graphics and Word Perfect.

\section{Activity 6: Using the Situation Analysis and the STls Studies}

The Zimbabwe buy-in required the Africa OR/TA Project to support the ERU to sub-contract and manage two operations research studies. The two studies, an assessment of 1) the Zimbabwe family planning program (Situation Analysis) and ii) the potential demand for and effectiveness of integrating STI/HIV management services within the ZNFPC clinic based family planning services, were used for training the ERU staff in different aspects of project management.

Principal investigators from the ERU participated in subcontracting procedures, project proposal development, project monitoring and evaluation. Instrument design, data collection and analysis proved useful components for training. At the end of the studies, the ERU researchers involved felt confident to undertake new projects because they had participated in the whole cycle of the project.

Utilisation and dissemination of results from studies were seen as important components of projects designed. With respect to the Situation Analysis Study, the study was used for the development of

\footnotetext{
${ }^{1}$ The percentage of the annual operating cost would be worked out when the strategies for other ZNFPC units are ready.
} 
the organisation's strategic plan for 1997 to 2002. Through a series of workshops conducted by different Units, the Situation Analysis results have been used to analyze the progress of the family planning and reproductive health program between 1991 and 1995.

At the end of 1997, plans were made to disseminate results to the provinces. In February 1998, two regional workshops were conducted for the provinces. Participants were drawn from the Ministry of Health, the ZNFPC, the municipalities and other local government authorities.

The same process of project management was adapted with respect to the STI project. However, for successful completion, this study required additional skills, which were not available within the ERU and thus had to be subcontracted from elsewhere. The study to assess the "Integration of STI services into FP service delivery at three ZNFPC clinics" required laboratory services to facilitate the diagnosis of STIs, a component of the study, which was sub-contracted. A statistics lecturer from a local university was sub-contracted to analyse the resultant data.

\section{DIFFICULTIES EXPERIENCED}

The scheduling of projects continued to present problems since some activities from other ZNFPC Units which require ERU's support had been incorporated in the ZNFPC's 1991 - 96 Strategy. Time constraints/low staffing levels resulted in the workshop to improve the "utilisation of service statistics for programme management" not being implemented. Some difficulties were experienced with some consultants who did not meet the agreed deadlines or submitted poor quality reports.

\section{FUTURE DIRECTION}

1. The assessment of the process of capacity building and the benefits derived from the computer and statistical training received positive assessment from members of the ERU and collaborating institutions. In particular, members of the ERU praised the course conducted by the University of Zimbabwe. For those with weak statistical backgrounds, new methods of data analysis were acquired while those who had not been refreshed for a long time, the course provided useful refresher training. A recommendation from both groups was that this type of collaboration between local University departments and the ERU should be continued.

2. Computer training, which was linked to city institutions, received less praise. The least favourable aspect of the training was that ERU members were left to organise their time to attend courses. Due to their heavy workload, the ERU staff found it difficult to take full advantage of the money set aside for this training. In future, it would appear more relevant not only to identify the courses required by each member but also to set up a timetable of attendance. 
3. ERU staff members continue to feel that they lack skills in presentation of research finding and report writing. In this regard, it is suggested that the ZNFPC should seek assistance of a communications specialist who will train them in critical issues in presenting material to different audiences. However, it should be noted that these skills are acquired more through practical experience than classroom training. The ERU is, therefore, urged to pursue an aggressive policy in identifying in-country institutions offering courses relevant to its requirements.

4. There is need for short-term research management training for ERU staff.

5. The ERU staff members continue to request long term training at postgraduate level. In view of the advanced research work that the organisation does and the technical support required of the Unit, it is recommended that some members of staff be trained at advanced levels. It is recommended that the ZNFPC should re-examine its policy on long term training in view of its needs. 